\title{
Evaluation of red cell distribution width (RDW) in diabetic nephropathy patients
}

\author{
Diyabetik nefropati hastalarında eritrosit dağılım aralığının (RDW) \\ değerlendirilmesi
}

Bülent BíliR ${ }^{1}$, Betül EKIz BíliR², Neslihan SOYSAL ATiLE², Mümtaz TAKIR ${ }^{3}$, Ahsen YILMAZ ${ }^{4}$, Murat AYDIN ${ }^{4}$

ABSTRACT

Diabetic nephropathy (DN) is an important cause of morbidity and mortality of diabetes mellitus (DM) patients. Inflammation has a pivotal role in DN pathogenesis. Red cell distribution width (RDW) is a current parameter which has been supposed to be a marker of ineffective erythropoiesis depending on chronic inflammation and neurohumoral activation. We aimed to compare levels RDW which is a marker of inflammation between DM patients with and without diabetic nephropathy and also evaluate the effect of diabetic nephropathy on RDW in a total of 101 type 2 DM patients (58 diabetic nephropathy patients and 43 patients without diabetic nephropathy). All clinical and laboratory data including BUN, creatinine, hemogram, fasting blood glucose, HbA1c, lipid profile, and blood pressure levels were recorded. SPSS 17.0 was used for the statistical analysis of data. RDW values of diabetic nephropathy patients was significantly higher than those of patients without diabetic nephropathy ( $p=0.032)$. Fasting blood glucose, HbA1c, LDLcholesterol levels and duration of diabetes were statistically significantly different (respectively $p=0.01,0.01,0.048,<0.001$ ), whereas triglycerides, HDL-cholesterol, creatinine levels, height and weight of the patients were not statistically significantly different (respectively $p=0.939,0.347,0.128,0.418,0.851$ ) between groups. Since $R D W$ index is a cheap and easy method its use can be recommended in the evaluation of inflammation and atherosclerotic process in diabetic nephropathy patients.

Keywords: Diabetes mellitus, diabetic nephropathy, RDW
Öz

Diyabetik nefropati, diyabetes mellitüsün (DM) en sık mortalite ve morbidite nedenlerindendir. Diyabetik nefropatinin patogenezinde ve ilerlemesinde inflamasyonun önemli bir rolü vardır. Eritrosit dağılım aralığı (RDW), kronik inflamasyon ve nörohumoral aktivasyona bağlı inefektif eritropoezisi gösterdiği düşünülen yeni bir risk belirteci olarak tanımlanmış güncel bir parametredir. Bu çalışmada, nefropatisi olan ve olmayan toplam 101 tip 2 DM (58 diyabetik nefropati ve 43 nefropatisi olmayan diyabetik) hastada, bir inflamasyon belirteci olarak RDW düzeylerini karşılaştırıp, diyabetik nefropatinin bu parametre üzerinde etkisini incelemeyi amaçladık. Hastaların üre, kreatinin, hemogram, açlık kan şekeri, HbA1c, lipid profili ve kan basıncı düzeyini içeren klinik ve laboratuvar verileri kaydedildi. Istatistiksel analizler SPSS 17.0 versiyonu ile yapıldı. Diyabetik nefropati grubunda RDW düzeyi nefropatisi olmayan diyabetik gruptan anlamlı olarak yüksek bulunmuştur $(p=0,032)$. Gruplar arası karşılaştırmada; $A K S$, $H b A 1 c$, $L D L$ ve DM yaşı açısından istatistiksel olarak anlamlı fark saptanırken ( $p$ değerleri sırasıyla; 0,01, 0,01, 0,048, <0,001), trigliserit, $H D L$, kreatinin, boy ve kilo açısından anlamlı fark saptanmamıştır (p değerleri sırasıyla; 0,939, 0,347, 0,128, 0,418, 0,851). Diyabetik nefropati hastalarında artan inflamasyonun ve aterosklerotik sürecin değerlendirilmesinde, maliyeti düşük bir indeks olan RDW'nin günlük pratikte kullanımı önerilebilir.
GiRiş

Tüm dünyada ve ülkemizde giderek artan sıklıkta görülen tip 2 diyabetes mellitus (DM) küresel bir sağlık sorunu haline gelmiştir. Dünyada 2035 yılı için beklenen global prevalans $\% 10,1$ iken $^{1}$, Türkiye'de 2013'te
Anahtar kelimeler: Diyabetes mellitüs, diyabetik nefropati, RDW

Received: 4.4.2016

Accepted: 16.5.2016

${ }^{1}$ Namık Kemal University, School of Medicine, Internal Medicine Department

${ }^{2}$ Ministry of Health Tekirdag State Hospital, Endocrinology and Metabolism Clinics

${ }^{3}$ Ministry of Health Istanbul Goztepe Education and Training Hospital, Endocrinology and Metabolism Clinics

${ }^{4}$ Namık Kemal University, School of Medicine, Biochemistry Department

Yazışma adresi: Bülent Bilir, Namık Kemal University, School of Medicine, Internal Medicine Department, Tekirdag

e-mail: bulentbilir@yahoo.com 
son dönem böbrek yetmezliği insidansı 100,000 diyabetik kişi-yılında 38,4 ile 804,0 arasında bulunmuştur $^{3}$.

Kırmızı kan hücresi dağılım genişliği (RDW= red cell distribution width), kırmızı hücre hacminin heterojenitesinin kantitatif bir ölçümüdür. RDW yüksekliği hücre boyutlarındaki heterojeniteyi gösterir (anizositoz). Bu durum eritropoezdeki bozulma ve eritrositlerin fragmantasyon ya da aglütinasyonla azalmasına bağlıdır ${ }^{4}$. RDW artışı kronik inflamasyon ve artmış oksidatif stresle birliktelik gösterir ${ }^{5}$.

RDW artışının genel populasyonda artmış kardiyovasküler mortaliteyle birlikte olduğu bilinmektedir ${ }^{6,7}$. Ayrıca, RDW artışının böbrek yetmezliği durumunda mortalite belirteci olduğu gösterilmiştir ${ }^{8,9}$. DM hastalarının en önemli morbidite ve mortalite nedenlerinin kardiyovasküler hastalık ve son dönem böbrek yetmezliği olduğu düşünüldügünde, RDW prognostik bir belirteç olarak akla gelmektedir.

Bu çalışmadaki amacımız, her hastada ölçümü kolay ve ucuz bir yöntem olan tam kan sayımını kullanarak, RDW'nin diyabetik nefropati hastalarında belirteç olarak kullanılabilirliğini değerlendirmektir.

\section{GEREÇ ve YÖNTEM}

Bir üniversite hastanesi iç hastalıkları polikliniğine başvuran ve tip 2 DM tanısı alan 140 hastanın dosyaları, alınan yerel etik kurul onayıyla, retrospektif olarak incelenerek, hastaların yaş, cinsiyet, boy, kilo, sistolik ve diyastolik tansiyonları kayıt altına alındı. Ayrıca bu hastalardan tıbbi gereklilik veya rutin kontrol nedeniyle istenmiş kayıtlı tam kan sayımı, açlık kan şekeri (AKŞ), glikozile hemoglobin (HbA1C), üre, kreatinin, lipid paneli kayıtlı olanlar, diyabetik nefropatisi (DN) mevcut olan ve olmayanlar olarak ayrılarak çaış̧ma için değerlendirmeye alındı. DN tanısı diyabetik hastalarda farklı zamanlarda 2 kez yapılan 24 saatlik idrar analizinde saptanan $\geq 30 \mathrm{mg} /$ gün persistent albuminüri ve farklı bir nefrolojik hastalığı olmayan hastalar olarak değerlendirilmiştir ${ }^{10}$. Günlük albuminüri düzeyi $<30 \mathrm{mg} /$ gün olan olgular non-nefropatik kabul edilmiştir. Yapılan dosya taramasında verileri eksik olanlar, tip 1 DM olanlar, malignite öyküsü olanlar, akut veya kronik enfeksiyonu olanlar, son dönem böbrek yetmezliği olanlar, karaciğer yetmezliği olanlar, koroner arter hastalığı ve serebrovasküler hastalık öyküsü olan toplam 39 hasta çalışma grubundan çıkarıldı. Sonuç olarak, toplamda 101 hasta çalışmaya dâhil edildi. Hastaların demografik bilgileri Tablo 1'de sunulmuştur.

\section{Biyokimyasal ölçümler}

Biyokimyasal ölçümler ve hemogram parametreleri 8-10 saatlik açlık sonrasında, sabah 08.30-9.30 saatlerinde alınan venöz kan örnekleri potasyum EDTA'lı tüplerde toplanarak, $30 \mathrm{dk}$. içerisinde çalışıldı. RDW ve diğer hemogram parametreleri, Pentra Dx Nexus 120 (İngiltere) cihazında analiz edilerek ölçüldü. Glikolize hemoglobin (HbA1C), HPLC metodu kullanılarak Primus Premier Trinity Biotech-Hb9210 marka otoanalizör ile High-density lipoprotein kolesterol (HDL), total kolesterol (TK), Trigliserid (TG), açlık kan şekeri (AKŞ) ve kreatinin Roche marka ticari kit kullanılarak Cobas e6000-e501 (Japan) cihazıyla ölçülmüştür. Low-density lipoprotein kolesterol (LDL), Friedewald formula kullanılarak hesaplanmıştır ${ }^{11}$.

\section{İstatistiksel İncelemeler}

Değişkenlere ait verilerin istatistiksel analizi için "SPSS statistics 17.0 Windows" paket programı kullanılmıştır. Çalışmada oluşturulan grupların dağılımı Kolmogorov Smirnov testi, ikili karşılaştırmalar ise Student-t testi (homojen gruplarda) ve Mann Whitney $U$ testi (heterojen gruplarda) ile yapıldı. Korelasyon değerlendirmesinde ise Pearson testi ile analizler yapılmıştır. $p<0,05$ değeri istatistiksel olarak anlamlı kabul edildi. Elde edilen sayısal değerler ortalamaıstandart sapma veya medyan, minimum-maksimum değerler olarak ifade edildi.

\section{BULGULAR}

Bu çalışma, 43 non-DN tip 2 DM'li (grup 1) ve 58 DN (grup 2) olmak üzere, toplam 101 hastada gerçek- 
Tablo 1. Demografik veriler ve ölçüm sonuçları.

\begin{tabular}{|c|c|c|c|c|c|c|c|}
\hline \multirow[b]{2}{*}{$\begin{array}{l}\text { Cinsiyet (Kadın/Erkek) } \\
\text { Yaş (yıl) }\end{array}$} & \multicolumn{3}{|c|}{ Grup I } & \multicolumn{3}{|c|}{ Grup II } & \multirow{2}{*}{$\begin{array}{c}\mathbf{p} \\
0,525 \\
0,560\end{array}$} \\
\hline & $\begin{array}{l}23 / 20 \\
49,64 \pm 11,3\end{array}$ & Min & Max & $\begin{array}{l}30 / 28 \\
50,37 \pm 10,8\end{array}$ & Min & Max & \\
\hline Boy $(\mathrm{cm})$ & 161,20 & 145,50 & 177,00 & 161,46 & 142,00 & 179,00 & 0,418 \\
\hline Ağırlık (kg) & 85,35 & 64,00 & 123,00 & 82,77 & 60,00 & 118,00 & 0,851 \\
\hline DM yaşı (yıl) & 5,42 & 1,00 & 26,00 & 10,95 & 1,00 & 33,00 & $<0,001$ \\
\hline Glukoz (mg/dl) & 160,35 & 80,00 & 430,00 & 203,07 & 96,00 & 432,00 & 0,01 \\
\hline HBA1C (\%) & 7,87 & 5,60 & 17,20 & 8,98 & 6,00 & 14,40 & 0,01 \\
\hline Total kolesterol (mg/dl) & 226,93 & 130,00 & 415,00 & 204,18 & 125,00 & 357,00 & 0,066 \\
\hline Trigliserit (mg/dl) & 184,14 & 36,00 & 466,00 & 180,26 & 53,00 & 623,00 & 0,939 \\
\hline HDL kolesterol (mg/dl) & 46,56 & 7,00 & 88,00 & 44,25 & 25,00 & 107,00 & 0,347 \\
\hline LDL kolesterol (mg/dl) & 143,51 & 76,00 & 291,00 & 123,65 & 66,00 & 230,00 & 0,048 \\
\hline Üre (mg/dl) & 29,79 & 12,00 & 44,00 & 36,24 & 22,00 & 76,00 & 0,010 \\
\hline Kreatinin (mg/dl) & 0,85 & 0,50 & 1,15 & 0,92 & 0,70 & 1,85 & 0,128 \\
\hline RDW (\%) & 14,32 & 11,30 & 18,20 & 15,09 & 12,80 & 22,10 & 0,032 \\
\hline
\end{tabular}

leştirildi. Grup 1 ve Grup 2 demografik, klinik ve biyokimyasal veriler açısından karşılaştırıldığında, DN grubunda RDW düzeyi non- DN gruptan anlamlı olarak yüksek bulunmuştur $(p=0,032)$ (Figür 1$)$.

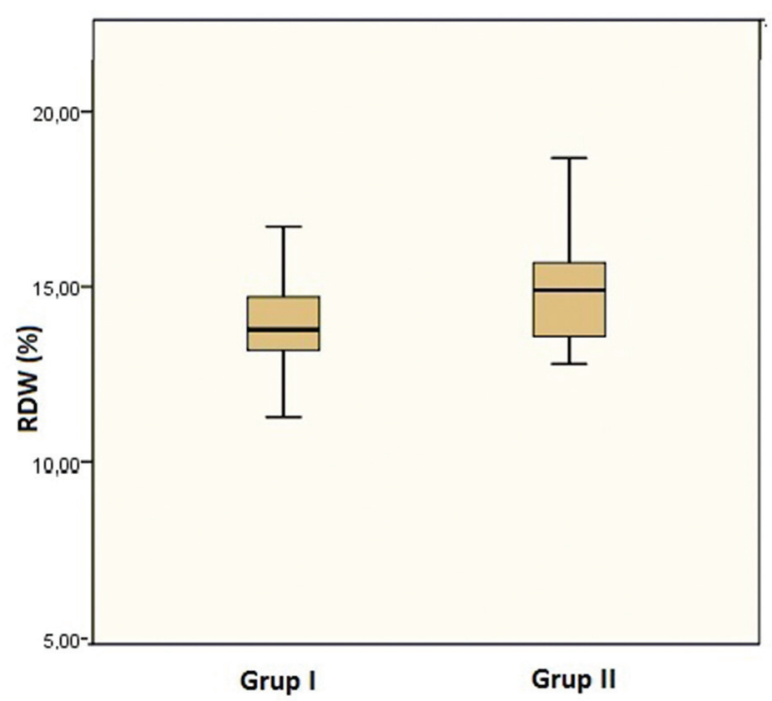

Figür 1. Grupların RDW \%'nin karşılaştırılması.

Gruplar arası diğer parametrelerin karşılaştırılmasında; AKŞ, HbA1C, LDL ve DM yaşı açısından istatistiksel olarak anlamlı fark saptanırken ( $p$ değerleri sırasıyla; $0,01,0,01,0,048,<0,001$ ), trigliserit, HDL, kreatinin, boy ve kilo açısından anlamlı fark saptanmamıştır ( $p$ değerleri sırasıyla; 0,939, 0,347, 0,126, 0,418, 0,851). Tüm demografik veriler ve ölçüm sonuçları Tablo 1'de sunulmuştur.
Yapılan Pearson korelasyon analizinde, diyabet yaşı, sistolik, diyastolik basınçlar ve total kolesterol ile RDW arasında pozitif korelasyon bulunmuştur (Tablo 2) (Figür 2).

Tablo 2. RDW düzeyi ile korelasyon.

\begin{tabular}{lcc}
\hline & \multicolumn{2}{c}{ RDW } \\
\cline { 2 - 3 } & $\mathbf{r}$ & $\mathbf{p}$ \\
\hline Diyabet Yaşı & 0,246 & 0,014 \\
Total Kolesterol & 0,019 & 0,023 \\
Sistolik basınç & 0,211 & 0,036 \\
Diyastolik basınç & 0,202 & 0,045 \\
\hline
\end{tabular}

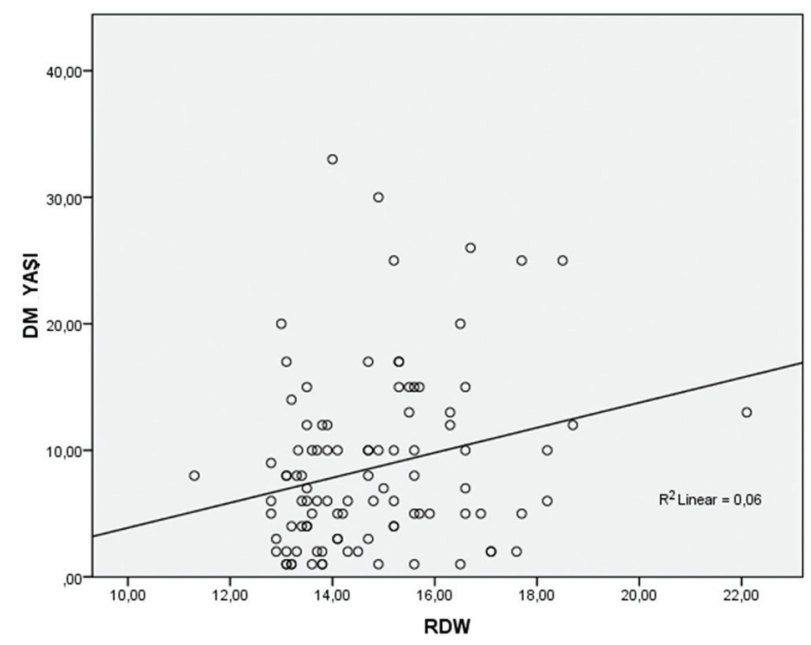

Figür 2. Grupların DM yaşı ile RDW 'nin korelasyonu. 


\section{TARTIŞMA}

$\mathrm{Bu}$ çalışmanın sonuçları değerlendirildiğinde, RDW seviyeleri, DN olan tip 2 DM'li hastalarda non DN tip 2 DM hastalarına göre istatistiksel olarak anlamlı düzeyde yüksek bulundu. Bu sonuçlar, RDW'nin tip 2 DM'de komplikasyon gelişimi ve dolayısıyla DN gelişimini yansıtabileceğini düşündürmektedir.

Son yıllarda ciddi bir halk sağlığı sorunu hâline gelen tip 2 DM ve komplikasyonlarına bağlı artan morbidite ve mortalite ile beraber bu konudaki çalışmalar da artmaktadır. Diyabetik nefropati, diyabetli hastalarda önemli bir komplikasyonu olup, gelişmiş ülkelerde hemodiyalize giren son dönem böbrek yetersizliği hastalarının 1/3'ünü oluşturmaktadır ${ }^{12}$.

DM ve komplikasyonlarını erken tespit edip, ilerlemesini engellemek ve artan ekonomik yükü azaltabilmek için yeni metotlar, belirteçler ve tedavi seçenekleri araştırılmaktadır.

RDW, son zamanlarda popüler bir araştırma konusu olup, çeşitli hastalıklar ve komplikasyonları ile ilişkisi incelenmektedir. Daha önceki yapılan çalışmalarda, enflamasyon belirteçleri ile RDW arasındaki güçlü ilişki gösterilmiştir. Enflamasyona bağlı gelişen eritrosit membran hasarı ve eritrosit maturasyon defektinin RDW'de artışa yolaçtığı düşünülmektedir ${ }^{13,14}$. Literatürde tip 2 DM hastalarında RDW düzeylerinin araştırıldığı birkaç çalışma mevcut olmakla beraber, diyabetin mikrovasküler komplikasyonlarıyla ilişkisinin incelendiği araştırmalar oldukça azdır.

Zhang ve ark. ${ }^{9}$ yeni tanı alan ilk tespit tip 2 DM hastalarında mikroalbuminüri ile RDW ilişkisini incelemişlerdir. MAU'si olan grupta RDW düzeyinin normoalbuminürik gruba göre anlamlı düzeyde yüksek olduğunu saptamış ve RDW'nin yeni tanı diyabette MAU için bağımsız bir risk faktörü olduğunu öne sürmüşlerdir. Böylece RDW nin diyabetik nefropati ve diyabetle ilgili diger komplikasyonları öngörmede etkili bir belirteç olabileceğini öne sürmüşlerdir.

Diyabetin bir diğer mikrovasküler komplikasyonu olan proliferatif diyabetik retinopatili 196 tip 2 diyabetli olgunun RDW düzeylerinin nefropati, nöropati ve periferik arter hastalığı ile ilişkisinin incelendiği bir diğer çalışmada, RDW düzeyi ile nöropati ve periferik arter hastalığı arasında bir ilişki bulunamazken, diyabetik nefropati ile arasında güçlü bir ilişki bulunmuş ve bu ilişkinin diyabet süresi, insülin direnci, metabolik sendrom varlığı, kan basıncı, diyabet tedavisi ve glisemik kontrolden bile bağımsız olduğu ortaya konmuştur. Normoalbuminürik diyabetik olguların RDW düzeyi mikro ve makroalbuminürik olguların RDW düzeyinden anlamlı düzeyde daha düşük bulunmuştur $^{15}$. Bu bulgular çalışma sonuçlarımızla da benzerlik göstermektedir.

Amerika Birleşik Devletleri'nde yapılan üçüncü NHANES (National Health and Nutrition Examination Study) çalışmasının verilerinin değerlendirildiği bir araştırmada ise, diyabetiklerde yüksek RDW değerlerinin kardiyovasküler hastalık ve nefropati gelişimi açısından daha yüksek risk taşıdığı ortaya konmuştur. Üriner albumin/kretainin oranı arttıkça RDW'nin arttığı saptanmıştır ${ }^{16}$. Çalışma sonuçlarımız da bu bulguları desteklemektedir.

Tip 2 diyabetin ilerlemesi ve komplikasyonların gelişmesi en önemli morbidite ve mortalite nedenlerindendir. Yeni belirteçler ile komplikasyon gelişimini erken tespit etmek ve bu komplikasyonların gelişim mekanizmalarını anlamak, komplikasyonların ilerlemesinin engellenmesi ve erken tedavi olanakları için katkı sağlayabilir. RDW'nin ucuz, basit ve kolay ulaşılabilir bir tetkik olması nedeniyle, bu konuda yeni bir belirteç olabileceğini düşündürmektedir. Çalışmamızın retrospektif ve kesitsel olması ve limitasyonudur, yapılacak yeni büyük ölçekli, prospektif çalışmalarla bu soruya yanıt aranabileceği düşüncesindeyiz.

\section{KAYNAKLAR}

1. Guariguata L, Whiting DR, Hambleton I, et al. Global estimates of diabetes prevalence for 2013 and projections for 2035. Diabetes Res Clin Pract 2014;103:137-149. http://dx.doi.org/10.1016/j.diabres.2013.11.002

2. Satman I, Omer B, Tutuncu Y, et al. TURDEP-II Study Group. Twelve-year trends in the prevalence and risk factors of diabetes and prediabetes in Turkish adults. Eur J Epidemiol 
2013;28:169-80.

http://dx.doi.org/10.1007/s10654-013-9771-5

3. Narres $M$, Claessen $H$, Droste $S$, et al. The Incidence of End-Stage Renal Disease in the Diabetic (Compared to the Non-Diabetic) Population: A Systematic Review. PLoS One 2016;11:e0147329.

http://dx.doi.org/10.1371/journal.pone.0147329. ECollection 2016.

4. Ryan DH. Examination of blood cells. In: Lichtman MA, Kipps $\mathrm{TJ}$, Seligsohn $\mathrm{U}$, et al, editors. Williams Hematology. $8^{\text {th }}$ ed. (Chap 2). New York, NY: The McGraw-Hill Companies, Inc.; 2010.

5. Ferrucci L, Guralnik JM, Woodman RC, et al. Proinflammatory state and circulating erythropoietin in persons with and without anemia. Am J Med 2005;118:128. http://dx.doi.org/10.1016/j.amjmed.2005.06.039

6. Pickup JC, Mattock MB, Chusney GD, Burt D. NIDDM as a disease of innate immune system: association of acute-phase reactants and interleukin- 6 with metabolic syndrome X. Diabetologia 1997;40:1286-1292. http://dx.doi.org/10.1007/s001250050822

7. Montagnana M, Cervellin G, Meschi T, Lippi G. The role of red blood cell distribution width in cardiovascular and thrombotic disorders. Clin Chem Lab Med 2011;50:635-641.

8. Yoon HE, Kim SJ, Hwang HS, et al. Progressive rise in red blood cell distribution width predicts mortality and cardiovascular events in end-stage renal disease patients. PLoS One 2015;10(5):e0126272. http://dx.doi.org/10.1371/journal.pone.0126272. eCollection 2015.

9. Zhang M, Zhang Y, Li C, He L. Association between red blood cell distribution and renal function in patients with untreated type 2 diabetes mellitus. Ren Fail 2015;37:659-63. http://dx.doi.org/10.3109/0886022X.2015.1010938

10. Mogensen CE, Chachati A, Christensen CK et al. Microalbuminuria: an early marker of renal involvement in diabetes. Uremia Invest 1985;9:85-95. http://dx.doi.org/10.3109/08860228509088195

11. Friedewald WT, Levy RI, Fredrickson DS. Estimation of the concentration of low-density lipoprotein cholesterol in plasma, without use of the preparative ultracentrifuge. Clin Chem 1972;18:499-502.

12. Hermon WH. Eye disease and nefropaty in NIDDM Diabetes. Diabetes Care 1990;13:24-29. http://dx.doi.org/10.2337/diacare.13.2.S24

13. Lippi G, Targher G, Montagnana M, et al. Relation between red blood cell distribution width and inflammatory biomarkers in a large cohort of unselected outpatients. Arch Pathol Lab Med 2009;133:628-32.

14. Weiss G, Goodnough LT. Anemia of chronic disease. N Engl J Med 2005;352:1011-1023. http://dx.doi.org/10.1056/NEJMra041809

15. Magri CJ, Fava S. Red blood cell distribution width and diabetes-associated complications. Diabetes \& Metabolic Syndrome: Clinical Research \& Reviews 2014;8:13-17. http://dx.doi.org/10.1016/j.dsx.2013.10.012

16. Malandrino N, Wu WC, Taveira TH, et al. Association between red blood cell distribution width and macrovascular and microvascular complications in diabetes. Diabetologia 2012;55:226-235.

http://dx.doi.org/10.1007/s00125-011-2331-1 